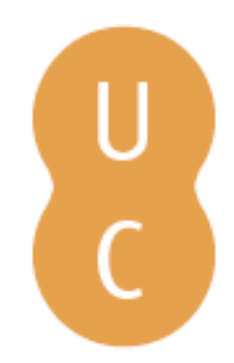

\title{
nombalina
}

\section{Aspetos da chegada do cinema em Moçambique}

\author{
Autor(es): $\quad$ Cruz, Jorge Luiz
}

Publicado por: Imprensa da Universidade de Coimbra

URL

persistente: URI:http://hdl.handle.net/10316.2/43879

DOI: $\quad$ DOl:https://doi.org/10.14195/978-989-26-1395-6_8

Accessed : $\quad$ 26-Apr-2023 06:44:16

A navegação consulta e descarregamento dos títulos inseridos nas Bibliotecas Digitais UC Digitalis, UC Pombalina e UC Impactum, pressupõem a aceitação plena e sem reservas dos Termos e Condições de Uso destas Bibliotecas Digitais, disponíveis em https://digitalis.uc.pt/pt-pt/termos.

Conforme exposto nos referidos Termos e Condições de Uso, o descarregamento de títulos de acesso restrito requer uma licença válida de autorização devendo o utilizador aceder ao(s) documento(s) a partir de um endereço de IP da instituição detentora da supramencionada licença.

Ao utilizador é apenas permitido o descarregamento para uso pessoal, pelo que o emprego do(s) título(s) descarregado(s) para outro fim, designadamente comercial, carece de autorização do respetivo autor ou editor da obra.

Na medida em que todas as obras da UC Digitalis se encontram protegidas pelo Código do Direito de Autor e Direitos Conexos e demais legislação aplicável, toda a cópia, parcial ou total, deste documento, nos casos em que é legalmente admitida, deverá conter ou fazer-se acompanhar por este aviso.

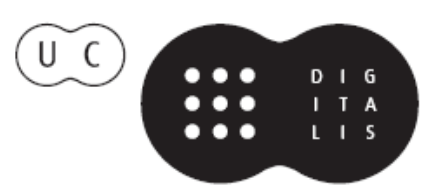



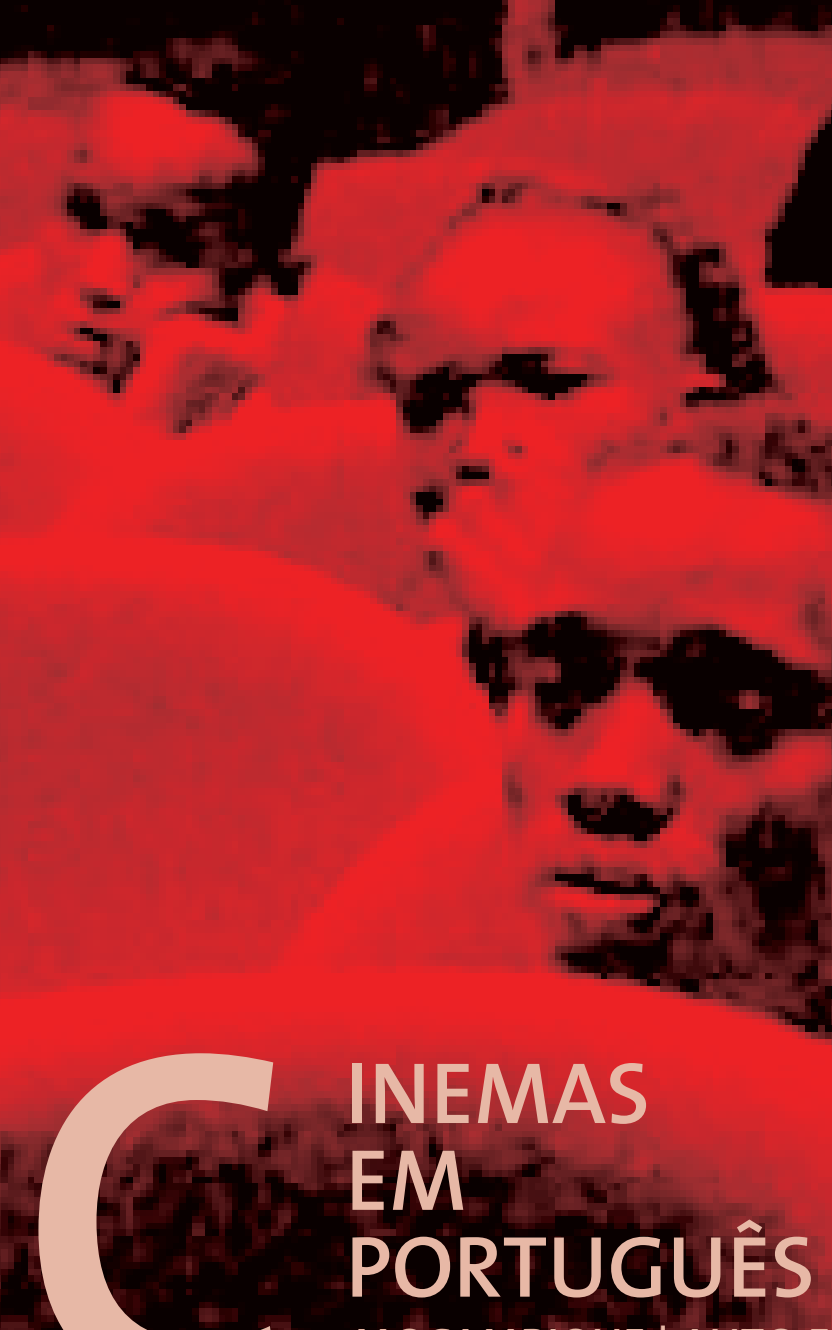

INEMAS

EM

PORTUGUÊS

MOÇAMBIQUE | AUTO E HETEROPERCEÇÕES

JORGE SEABRA

COORDENAÇÃO 


\section{ASPETOS DA CHEGADA DO CINEMA \\ EM MOÇAMBIQUE}

Jorge Luiz Cruz Universidade Estadual do Rio de Janeiro Laboratório de Cinema e Vídeo

Seboipepe, bela índia da tribo antropófaga Tupinambá no filme Como era gostoso o meu francês (1971), do Nelson Pereira dos Santos, magnificamente interpretada pela Ana Maria Magalhães, dá o tom do discurso que proponho neste texto, quando, no fim do filme, saboreando a carne do seu francês, olha diretamente para a câmera, para nós, reafirmando a sua cultura.

\section{O que se via}

O cinema chega em Moçambique, como na maioria dos países, pela iniciativa de alguns visionários e comerciantes que queriam explorar a então nova tecnologia a serviço do entretenimento. Conforme anota Convents, "no início do século XX o engenheiro civil português José Onofre aluga às autoridades coloniais em Lourenço Marques, na Praça 7 de março, uma barraca para apresentar filmes" (Convents, 2011, p. 50), e o nomeia Salão Onofre. Poucos anos depois, a matéria intitulada Novos cinematógrafos, em O futuro, de 05/12/1907, informa a inauguração do 
[...] novo cinematógrapho na Rua Lapa [nomeado então Salão Edison], junto ao estabelecimento do Sr. Manuel Rodrigues. Amplo, com ventoinhas elétricas e, sobretudo, com uma grande variedade de fitas recebidas diretamente da casa Pathé. São proprietários os Srs. Manuel Augusto Rodrigues e Catena. No Café Paris também vai começar a funcionar um outro cinematógrapho. Ao que consta, um conhecido fotógrafo desta cidade instalará brevemente outro aparelho a funcionar e realizar-se-á no próximo dia 11 no Teatro Primeiro de Janeiro a primeira sessão experimental. [E a matéria continua, pois] parece que mais dois conhecidos comerciantes vão também inaugurar brevemente outro cinematógrafo (Convents, 2011, p. 50).

Estes exibidores trabalhavam com imensas dificuldades, além do crescente número de salas na cidade, o seu público era reduzido à população de pele clara, pois, como anota Reynolds, os "[...] primeiros cinemas moçambicanos nunca foram destinados a atender as necessidades de lazer da população negra” (Reynolds, 2015, p. 23) que era numerosa, portanto é "desnecessário dizer, que não se esperava [nestas salas] as presenças dos mineiros negros, dos estivadores portuários e dos trabalhadores Chibalo ${ }^{1}$ rurais" (Reynolds, 2015, p. 23). Estas salas tinham também dificuldades de ordem tecnológica, pois, mesmo com as sessões destas salas sendo à noite, por volta das 21 horas, o Cinematógrapho do Sr. Onofre, por exemplo, pagou o preço de ser pioneiro, e embora a população estivesse "entusiasmada a ver a maravilha exibida dentro daquele barracão, [...] sai dali sufocada de calor, pois Onofre, nas pressas, esquecera-se de instalar ventoinhas. [Mas] o empresário corrige logo o erro, pelo que se depreende das

1 Trabalhadores em regime de semiescravidão. 
colunas do jornal O futuro, de 31 de Novembro de $1907^{2}$, além disso, a luz elétrica era precária e, parece-nos, mal distribuída, os filmes eram

mal iluminados, por vezes desfocados ou muito tremidos, [e] era frequente o filme partir-se ao meio do espetáculo ou então falhar a corrente elétrica que alimentava quase sempre mal, a maquineta de projeção. Acendiam-se velas. E quando a avaria era mais séria, o proprietário do Cinematógrafo cumprimentava os espetadores, desmanchava-se em cortesias, pedia desculpas pelo sucedido e thes devolvia o preço dos bilhetes ou revalidava-os para o próximo espetáculo. Ninguém se zangava com o percalço ${ }^{3}$.

Cabe observar ainda que já se exibiam então fitas coloridas, mesmo em Moçambique, isto "pelo primitivo processo em que as operárias parisienses, hábeis e mal remuneradas, coloriam pacientemente a pincel, como nos bilhetes postais da época, os milhares de quadradinhos de celulóide nos laboratórios da Pathé" 4 , tudo com o objetivo de causar sensação e, é claro, para levar o público às salas.

Também com esta intenção, de conquistar o público, as salas apresentavam programações mistas, isto é, mesclavam a novidade, o cinematógrafo, com o tradicional e conhecido, neste caso, a música. Assim, no número 94 do jornal moçambicano Vida Nova, publicado no dia 1 de agosto de 1908, temos anunciada a programação do Salão Edison:

Todas as noites, exibição das mais recentes e sensacionais novidades cinematographicas, intercaladas com um bello programma musical pela orchestra Fiore" (p. 2), com o seguinte programa,

\footnotetext{
2 Em http://maputo120anos.9f.com/gil.htm.

3 Idem.

${ }^{4}$ Idem.
} 
que intercala as projeções com números musicais: $1^{\circ}$ Orchestra: Overture - Caliph of Bagdad, Boieldien; $2^{\circ}$ Cavalheiro conquistador; $3^{\circ}$ Orchestra: La Gioconda, Ponchielli; $4^{\circ}$ Contra mestre incendiário; $5^{\circ}$ Orchestra: The catch of the season, Haines; $6^{\circ}$ Bombeiro em serviço; $7^{\circ}$ Orchestra: Ilda, Cohen; $8^{\circ}$ Vingança de louco; $9^{\circ}$ Orchestra: Ave Maria, Mascheroni; $10^{\circ}$ Noite de bodas; $11^{\circ}$ Beijo d'amor' .

Conforme atesta a página Maputo 120 anos, já referida, o Cinematógrapho cuidava muito bem da bomboniére desde os primórdios e já vendia guloseimas nos intervalos da programação. E os senhores Onofre e Rodrigues também concorriam nas variedades, pois, ainda segundo o site,

esses salões [...] não se aguentavam só com fitas. Davam-se aí também bons espetáculos de teatro e concertos [...]. Enquanto José Onofre anunciava, em 1908, a apresentação da sensacional Madame Nellie Pearse, que ele fora buscar a Johannesburg para 'cantar canções escocesas e inglesas' no seu salão, [...] o Manuel Rodrigues, que era homem de opiniões, anunciava [...] a apresentação das insinuantes espanholas 'Irmãs Truias', que mandara vir de Lisboa (Ibidem).

Estas primeiras salas da então Lourenço Marques ficaram pequenas e o Sr. Manuel Rodrigues inaugurou em 8 de setembro de 1913, no lugar onde funcionava o Salão Edison, à rua Lapa, o Teatro Gil Vicente, que "foi o primeiro cinema a sério em Lourenço Marques, com uma lotação para 1000 pessoas, segundo projeto do arquiteto Ferreira da Costa” (Ibidem). Esta sala tem inequívoca importância para a história da exibição audiovisual do país, pois "em março de 1931 instala

\footnotetext{
5 “Salão Edison". Vida nova. Lourenço Marques: n 94, 1/8/1908, p. 2.
} 
Manuel Rodrigues, em exploração permanente, a primeira aparelhagem sonora, então a última maravilha do cinema, timidamente iniciada em 1926 pela Vitaphone, em Nova York" (Ibidem).

Segundo Convents, "o anuário de Lourenço Marques de 1914 indica duas salas de cinema: o Teatro Varietá, na rua Araújo, com 1803 lugares [iniciativa de dois italianos, o empreitero Pietro Buccelato e o comerciante Angelo Brussoni], e o Teatro Gil Vicente, na rua Lapa, para 872 espectadores" (Convents, 2011, p. 55), e que "estas duas salas programam filmes todas as noites" (Idem), o que demonstra claramente o sucesso deste tipo de entretenimento e ainda, segundo Convents, em seguida as autoridades já começam a cobrar impostos das salas de cinema ${ }^{6}$.

Os moçambicanos do interior também tiveram desde cedo contato com o cinema, é que "ao lado do cinema comercial existe desde os anos quarenta também um cinema ambulante organizado pelas autoridades como em Portugal" quarenta os indígenas do interior descobrem também o cinema com o cinema ambulante do português Thomaz Vieira" (1878-1974)" para além da "sua atividade como ator, a que se dedicou na primeira fase da sua vida ativa, aos 53 anos virou-se para a difusão do cinema e criou em Moçambique a primeira companhia de cinema ambulante, percorrendo com um carro caravana (mais tarde batizado Quo Vadis) todas as cidades e sertões do interior daquela colônia, durante mais de 35 anos. Em 1967, publica um livro de memórias, 'autêntico testemunho de vida, um texto antropológico de um observador atento da sociedade do seu tempo'" (Alvarez, sd, p. 79). Cabe ressaltar ainda que este livro foi "escrito e publicado por ele mesmo" (Freire, 2009)

\footnotetext{
${ }^{6}$ Ibidem. Convents informa ainda que "o valor do imposto é calculado em função do número de lugares da sala" (Idem, p. 55) e não, como é hoje, sobre o número de ingressos vendidos.

${ }^{7}$ Idem, p. 181, nota ${ }^{\circ} 357$.

8 Idem, p. 181.
} 
e foi intitulado O homem que morreu 4 vezes... Memórias de um actor (Vieira, 1967). Assim, Convents dá como "[...] certo que, nos finais dos anos quarenta, os cinemas ambulantes, privados e do governo colonial, aparecem nas cidades e aldeias no interior de Moçambique" (Convents, 2011, p 181). Neste sentido, por fim, Power anota que

the idea for a cinema ambulante scheme (which was later linked to Portugal's "psyco-social action" plan) originated with advertising agents who applied to the colonial state in the 1960s for permission to screen short advertising films to the indigenous populations of the regions os Manica, Sofala, Gaza and Lourenço Marques (Power, 2004, p. 268).

\section{O que se fazia}

Convents afirma que "até hoje não se sabe claramente quando é que as câmaras chegaram a Moçambique para registrar imagens do país" (Convents, 2011, p. 259), mas cita Matos-Cruz e o filme Jogos de Malabares em Lourenço Marques, vendido para a empresa de Germano Alves, do Rio de Janeiro, que o apresentou no Teatro Juiz de Fora, na cidade de mesmo nome, em Minas Gerais, no dia 23 de julho de 1897, a primeira exibição do cinematógrafo no estado, em espetáculo com "muitas atrações trazidas pela companhia de variedades de Germano Alves [...]" e "que apresentava números musicais, teatrais e circenses e tinha o cinematógrapho como principal atração" (Lino, 2009, p. 93). Sobre a exibição deste filme em Juiz de Fora, temos ainda a transcrição de trecho da matéria publicada no dia 24 de julho de 1897, no jornal o pharol, que assim apresenta o cinematógrapho:

Neste maravilhoso aparelho apresentará o senhor H. Picloet quadros de comprimento do pano de boca do teatro com auxílio de luz elétrica, sem a menor oscilação. Títulos dos quadros: Os 
banhistas na Figueira da Foz; Uma partida no jogo do solo; Uma distração no palácio de Cristal; Jogos de malabares em Lourenço Marques; O czar em Paris; O patinador grotesco; Os lanceiros da rainha em Lisboa; Batalha de neve em Lyon ${ }^{9}$.

Também Matos-Cruz (1999) faz uma referência ao filme, quando anota que "o cinema em Moçambique constitui, historicamente, uma das primeiras referências de âmbito colonial numa filmografia sobre Portugal - curiosamente assinalada no Brasil, onde a Empresa Germano Alves apresentou Jogos Malabares em Lourenço Marques (1897)”. Convents afirma, por conta deste filme, que "o certo é que já em 1897 um cineasta está ativo em Moçambique" (Convents, 2011, p. 259), e anota também que, "provavelmente, o filme Os mergulbadores na África Portuguesa foi também realizado em Moçambique" (Convents, 2011, p. 259), mas devo alertar que não há nenhuma referência aos diretores e nem às suas procedências em nenhum registro ou publicação até agora encontrado. $\mathrm{Na}$ verdade, nem sabemos se os filmes foram feitos por portugueses, ainda que esta seja a maior possibilidade.

O que sabemos, no entanto, é que entre as primeiras realizações cinematográficas em Moçambique, assim como em toda a África de língua portuguesa, algumas tinham o objetivo de justificar a exploração das então colônias para o resto da Europa, que ainda brigavam por estes espaços e Portugal temia ser questionado e perdê-las para outros países, ou terem seus portos ocupados durante a Primeira Guerra Mundial (Convents, 2011, p. 260).

Desde o início do século XX, então, os portugueses realizaram diversos filmes de propaganda nas suas colônias ${ }^{10}$, é o caso da Expedição cinematográfica do Catanga até à Beira, 1920; e depois outras ações

\footnotetext{
${ }^{9}$ Apud Sirimarco, Martha. João Carriço, o amigo do povo. Juiz de Fora: FUNALFA Edições, 2005.

${ }^{10}$ Sobre a produção de filmes de propaganda proposta pela International AudioVision - IAV -, v. Piçarra, 2013.
} 
mostram as intenções dos portugueses de divulgar Moçambique e o seu principal porto, em Lourenço Marques, com filmes realizados para serem exibidos nas grandes exposições europeias. Convents destaca uma produção local em Moçambique, indicada pelas "atividades de João Fernandes Tomáz, estabelecido em Lourenço Marques desde 1929/1930" (Convents, 2011, p. 272), que concluiu em 1931 a ficção A grande actriz, e cooperou também "nos documentários No país das Laurentinas-colonos, de 1934, de Ismael Da Costa, Dragões de Moçambique, de Aníbal Contreiras, e Missões Franciscanas em Moçambique, de Aquilino Mendes"11.

Matos-Cruz (1999) cita alguns filmes realizados por portugueses nas colônias, da qual recordamos os realizados em Moçambique: em 1931, A grande atriz, de João Fernandes Tomáz, do qual, "Moura12 observa que $A$ grande actriz, deve ser considerado como o primeiro filme de ficção realizado em Lourenço Marques e que esse esforço e a 'boa vontade' empregados desculpam as deficiências e merece, por isso, 'a simpatia carinhosa de todos nós'"13. Por volta de 1939, Paulo de Brito Aranha realizou A segunda viagem triunfal do chefe do estado Óscar Carmona às colônias da África ocidental; em 1953, Jorge Brum do Canto realizou Chaimite, filme sobre o qual já foram realizados alguns importantes estudos (entre eles, destacamos o livro de Jorge Seabra, África nossa, o império colonial na ficção cinematográfica portuguesa 1945-1974), e Carlos Marques realizou Chikwembo! Sortilégio africano, conforme anota Matos-Cruz, "referenciado como 'o primeiro filme português inteiramente filmado em África”" (Matos-Cruz,1999, p. 39); em 1964, Rico de Souza filmou Baiete!!! Moçambique, o qual, segundo Matos-Cruz, foi uma produção local de Courinha Ramos que registrou "a chegada de Américo Thomaz, Presidente da República,

\footnotetext{
11 Ibidem.

12 Hélio Moura, da revista portuguesa Cinéfilo.

13 Apud Convents, 2011, p. 273.
} 
à capital Lourenço Marques, seguindo-se visitas à Barragem Oliveira Salazar e ao Parque Nacional da Gorongoza" (Matos-Cruz,1999, p. 39), e Catembe, 7 dias em Lourenço Marques, de Faria de Almeida ${ }^{14}$; em 1968, Knock-out, de Vic/Viriato Barreto, esta, também segundo Matos-Cruz, "uma aventura criminal cujo elenco incluía elementos da Etnia Bando, em experiência de coprodução, sem continuidade, com a África do Sul"15; em 1970, Jorge de Souza realizou Limpopo; e Pascal-Angot realizou O porquê - Cabora Bassa. Num breve panorama sobre o cinema moçambicano, Matos (2006) destaca os filmes realizados sobre as viagens às colônias de África, os de incentivo à África branca, os documentários realizados nas colônias e as encenações das guerras de ocupação, os filmes produzidos para exposições e outros eventos realizados na metrópole.

Neste contexto, então, dois nomes são importantes na formação desta cinematografia, parece-me já, bastante vigorosa, António de Melo Pereira e o António Jorge Courinha e Ramos ${ }^{16}$. O primeiro, Melo Pereira é apontado como "o pioneiro do cinema em Moçambique"17, nasceu em Portugal, trabalhou em realizações dos cineastas portugueses Leitão de Barros e Jorge Brum do Canto. Ao participar da filmagem de Chaimite $^{18}$, realizada em Moçambique, acabou por se fixar em Lourenço Marques. Mais tarde, em agosto de 1955, iniciou a produção das Atualidades moçambicanas, cinejornal mensal regularmente até ao ano de 1969. Realizou também alguns tantos documentários, entre eles Cabora-Bassa 1 (1971) e O vale do Zambeze (1973). Outro produtor e realizador que atua em Moçambique mere-

\footnotetext{
${ }^{14}$ Ver, entre outros, Piçarra 2009a e 2009b.

15 Idem.

16 Cabe ressaltar que às vezes o nome aparece grafado como Courinha Ramos e outras como Courinha e Ramos, aqui adotamos, então, a primeira, que encontramos mais vezes.

17 Ver Livro de ouro do mundo português: Moçambique, 1971, p. 64.

18 1953, disponível em https://www.youtube.com/watch?v=zRoLhuBd-bs).
} 
ce destaque, o moçambicano Courinha Ramos que, segundo França, "criou o primeiro laboratório e o primeiro estúdio em Moçambique" (2013), respectivamente o Labfilm e a Somar Filmes, esta em 1968. Ele também realizou curtas-metragens, como Aprenda a viver, realizado ainda na década de 1950; documentários, como Alicerces do futuro (1964); e produziu, durante sete anos, "cerca de 250 edições do Visor Moçambicano, o seu jornal cinematográfico" (Convents, 2011, p. $295)^{19}$, realizado de modo amador e improvisado, pois "primeiro não havia dinheiro, segundo os técnicos eram poucos" (Almeida, 2008), e Almeida ressalta que "foi assim, que quinzenalmente apareceu no cinema o Visor moçambicano, que focava as principais actualidades, sob o patrocínio de certas empresas locais", e acrescenta que "posteriormente (...) apareceu, e também quinzenalmente, mas desfasado, o Visor desportivo, este patrocinado integralmente pela cerveja 2M, portanto todas as semanas havia um documentário de cerca de 10 minutos de duração" (Almeida, 2008).

Ainda segundo Convents, "o sucesso da empresa do Courinha Ramos é, sem dúvida, possível porque aproveita as facilidades dos laboratórios sul-africanos [estúdios da African Films, em Killarny, Johannesburg], mais baratos que os de Lisboa, sobretudo na segunda metade dos anos cinquenta" (Convents, 2011, p. 295), e, por não receber apoio das autoridades coloniais da província, Courinha Ramos buscava "[...] patrocínios no mundo do comércio e da indústria, o que não é sempre fácil, mas assim fica 'um pouco' fora da ideologia explícita do Estado Novo, marca que caracteriza mais as produções do Melo Pereira que é financiado pelo governo" (Convents, 2011, p. 295). Segundo Almeida, foi produzido pela Somar "o primeiro filme Moçambicano, o Zé do burro [1972, de Eurico Ferreira, e produção de Courinha Ramos], com esse grande (em tudo, menos em altura)

19 Ver uma das edições do ano de 1973 em https://www.youtube.com/ watch? $v=j b 4 Q$ SmufWxc. 
artista José Bandeira. Segue-se o O explicador de matemática [1977, produção e direção de Courinha Ramos], com Diniz, que na altura era o gerente do Cinema Avenida. O último foi Deixem-me ao menos subir as palmeiras [1972, de Joaquim Lopes Barbosa, produção de Courinha Ramos], que já não foi exibido em Moçambique, porque a P.I.D.E. [a Polícia Internacional e de Defesa do Estado, de Portugal, foi criada pelo Decreto-Lei número 35.046, em 22 de outubro de 1945, e durou até 24/11/1969, quando foi substituída pela DGS, Direção Geral de Segurança, e esta durou até a Revolução dos cravos, a 25 de abril de 1974] não o autorizou" (Almeida, 2008). Por estas poucas linhas, enfim, podemos verificar a importância, tanto de Melo Pereira, quanto de Courinha Ramos para a arrancada do cinema em Moçambique ainda no período colonial.

Não temos notícias de filmes realizados em regime de coprodução na então colônia, mas ainda nos primeiros anos depois da independência, o filme de ficção O tempo dos leopardos (1985, 95 minutos, Moçambique/Yuguslávia), de Zdravko Velimorovic, foi realizado neste regime em Moçambique.

Cabe destacar ainda que, conforme anota Convents, dentre as produções realizadas "antes dos anos sessenta, uma das caraterísticas das imagens produzidas em Moçambique é a presença mínima da população indígena: está quase ausente e quando aparecem africanos na tela raramente são identificados, sendo considerados como uma massa negra impessoal" (Convents, 2011, p. 259), que "a maioria destes filmes produzidos na colônia, e depois na província, não são destinados a um público indígena, mas sim realizados para o português ou para o ocidental" (Convents, 2011, p. 259), e ainda que "as imagens, na sua maior parte, são um olhar sobre os recursos naturais, sobre as possibilidades econômicas e o desenvolvimento material de Moçambique colonial" (Convents, 2011, p. 259). 


\section{Palavras finais}

Mais tarde, após suas independências, dentre os países africanos de língua portuguesa, Moçambique foi, provavelmente, o primeiro a começar a organizar o cinema, isto com contribuições importantes para o audiovisual em África, desde as experiências dos Kucha Kanema, o nascimento do cinema, e através da criação do Dockanema, Festival do filme documentário, desde 2006, em Maputo, um dos grandes eventos cinematográficos da África, e que está suspenso desde 2013, quando o seu criador e primeiro diretor, Pedro Pimenta, passou "a responsabilidade para a produtora Cine Vídeo Moçambique, da brasileira Cine Vídeo Internacional" 20.

Cabe ressaltar ainda que os primeiros anos após a independência de qualquer país são de grandes dificuldades, geralmente são disputas internas, falta de abastecimento entre outros problemas, geralmente graves, assim, também Moçambique, foi marcado por intensa guerra civil desde 1977 até 1992, e só depois, em 1994, o país realizou as primeiras eleições multipartidárias e desde então tem-se mantido politicamente estável. De qualquer forma, nesta difícil passagem de colônia para um país independente, no cinema, como Diawara anotou,

in terms of production, in 1975 Mozambique had neither filmmakers nor production facilities. The film need of the country was therefore filled by foreign directors like Robert Van Lierop from the United States and Fernando Silva, Ceklso Lucas, and Jose CelsoCorrea from Brazil. There were also Cuban and Leftist filmmakers from Europe. Silva made a documentary depicting the history of the struggle leading to indepedence, Um ano de independência (1975). In 1976, he directed Mapi on the attack of such Mozambican villages

${ }^{20}$ Lusa, 09/08/2013. 
as Mapai by the Rhodesian army of Ian Smith. The film explains that the terrorist attacks were motivated by the support given by Mozambique to the liberation of Zimbabwe. In 1977, Lucas an Correa directed a $150 \mathrm{mn}$ documentary entitled 25, on 'all the stages of tyhe liberation struggle led by FRELIMO from june 25, 1962, when the movement was founded, to june 25, 1964, the date of the first crash with the colonial regime, to April 25, 1974, when the colonial regime was defeated' 21 .

Neste percurso, então, já no ano de 1981, conforme observa Convents (2011), o então assistente do INC Pedro Pimenta e o cineasta Camilo de Souza viajam para os Estados Unidos para apresentarem "os primeiros filmes realizados em Moçambique [e] o objetivo desta ação é a angariação de fundos para adquirir material de cinema [...]" (Convents, 2011, p. 468). Os filmes exibidos foram: o documentário Estas são as armas (1978, 50 minutos), realizados pelos estudantes do Instituto Nacional do Cinema - INC - Moçambique, sob supervisão do brasileiro Murilo Salles e do escritor moçambicano Luís Bernardo Honwana; Mueda, memória e massacre (1979, 80 minutos, ficção), de Rui Guerra, e as curtas-metragens Que venham (1981, 25 minutos), de José Cardoso, Unidade em festa (10 minutos), de Luís Simão, e ainda os filmes Operação Leopardo e Ofensiva, ambos de Camilo de Souza com cerca de trinta minutos cada um.

Por fim, cabe destacar que após a independência e depois de longo e turbulento período de alianças e rompimentos, muitos filmes foram realizados no país, entre eles, O vento sopra do norte (1986, 97 minutos, 16 mm., INC-Moçambique), de José Cardoso; $A$ tempestade da Terra (1996, 112 minutos, Portugal), com direção de Fernando d'Almeida e Silva, na década de 1990; e O jardim do outro homem (2006, 80 minutos, coprodução entre Moçambique, Portugal

21 Hennebelle, p. 173, in Diawara, 1992, p. 94. 
e França), de Sol de Carvalho, em filme que mostra a história de uma jovem estudante que é forçada a fazer favores sexuais ao seu professor para ingressar no curso de medicina.

\section{Referências}

ALMEIDA, Humberto. "Entardecer: António Jorge Courinha Ramos, Um homem de sete ofícios, sempre voltado para a rádio, cinema e escrita”. 28 abr 2008, em http://comunidade.sol.pt/blogs/meiablue/archive/2008/04/26/Um-homem-desete-of_ED00_cios_2C00_-sempre-voltado-para-a-r_E100_dio_2C00_-cinema-eescrita.aspx. Acesso em 20/08/2008.

ARMES, Roy. O cinema africano ao norte e ao sul do Saara, 2012 (parte 1), em http://www.buala.org/pt/

afroscreen/o-cinema-africano-ao-norte-e-ao-sul-do-saara-1-parte. Acesso em $13 / 08 / 2015$.

- O cinema africano ao norte e ao sul do Saara, 2012 (parte 2), em http:// www.buala.org/pt/

afroscreen/o-cinema-africano-ao-norte-e-ao-sul-do-saara-2-parte. Acesso em $13 / 08 / 2015$.

. O cinema africano ao norte e ao sul do Saara, 2012 (parte 3), em http:// www.buala.org/pt/

afroscreen/o-cinema-africano-ao-norte-e-ao-sul-do-saara-3-parte. Acesso em 13/08/2015.

BARBOSA, Joaquim Lopes. Entrevista a Gabriela Moreira. Cadernos Kugoma. Moçambique, Fórum de cinema de curtas-metragens, Ano 0, n. 0, jul. 2013. p. 36-48.

CONVENTS, G. Os moçambicanos perante o cinema e o audiovisual: uma história político-cultural do Moçambique colonial até a República de Moçambique (18962010). Maputo: Edições Dockanema/Afrika Film Festival, 2011.

COTRIM, Teresa; CURTO, Pedro Ramada. Moçambique: primeiro guia em português. Alfragide: LeYa, 2011. p. 70. Em https://books.google.com.br/books?id=isHNd mQW10wC\&pg=PA70\&lpg=PA70\&dq=Teatro+Variet\%C3\%A1+-+rua+Ara\%C3\%BAjo+$+\mathrm{Mo} \% \mathrm{C} 3 \% \mathrm{~A} 7 \mathrm{ambique} \&$ source=bl\&ots=d2JCw4j-on\&sig=NsXesjiZtrqykNtAMNBv 0j4xRMg\&hl=ptBR\&sa=X\&ved=0CCgQ6AEwAmoVChMIoIzMjJDvxwIVQpSQCh11 AAel ${ }^{*} \mathbf{V}=$ onepage\&q=Teatro $\% 20$ Variet $\%$ C3\%A1\%20-\%20rua $\% 20$ Ara $\%$ C3\%BAjo $\% 20$ -\%20Mo\%C3\%A7ambique\&f=false. Acesso em 11/09/2015.

DIAWARA, Manthia. African cinema: politics $\&$ culture. Indiana: Indiana University Press. 1992.

FRANÇA, Alex Santana. "O cinema moçambicano pós-colonial: outros olhares, outros discursos”. Crioula. Revista eletrônica dos alunos do Curso de Pós-graduação em Estudos comparados de literaturas de língua portuguesa - DLCV/FFLCH/ USP. N. 13 (2013). p. 1-10.

FREIRE, António Abreu. O homem que morreu quatro vezes. 16/05/2009. Em http:// antonioabreufreire.bloguepessoal.com/165899/O-homem-que-morreu-quatro-vezes/, acesso em 28/08/2015. 
LINO, Sônia Cristina. "Cinematographo: doença da moda". Revista do arquivo publico mineiro. Belo Horizonte, v. 1, n. 1, jan./jun.2009. p. 90-103.

LIVRO de ouro do mundo português: Moçambique, 1971, em http://issuu.com/ gotael/docs/livro_de_ouro_do_mundo_portugu_s_-_mo_ambique_1971, acesso em 18/08/2015.

MATOS, Patricia Ferraz de. "Imagens da África? Filmes e documentários relativos às antigas colônias africanas (primeira metade do século $\mathrm{XX}$ )". V Congresso de Estudos Africanos no mundo ibérico. África: compreender trajectos, olhar o futuro, ocorrido de 4 a 6 de maio de 2006. Em https://www.academia.edu/3546039/ Imagens_de_\%C3\%81frica_filmes_e_document\%C3\%A1rios_portugueses_ relativos_\%C3\%A0s_antigas_col\%C3\%B3nias_africanas_primeira_metade do_s\%C3\%A9culo_XX_._V_Congresso_de_Estudos_Africanos_no_Mundo_ Ib\%C3\%A9rico_\%C3\%81frica_compreender_trajectos_olhar_o_futuro. Acesso em $12 / 08 / 2015$.

MATOS-CRUZ, José de. "Cinema luso-moçambicano". Revista Camões, n. 6, 1999, p. 38-45. Em http://cvc.instituto-camoes.pt/conhecer/biblioteca-digital-camoes/ revista-no06-pontes-lusofonas-ii/1362-1362/file.html, acesso em 13/08/2015.

PIÇARRA, Maria do Carmo. Cinema do império: o "fado tropical" na propaganda. In: PIÇARRA, Maria do C.; ANTÓNIO, Jorge (coord's). Angola: o nascimento de uma nação. V. 1, O cinema do império. Lisboa: Guerra e Paz, 2013. p. 15-52.

. Catembe ou queixa da jovem alma censurada, entrevista a Faria de Almeida. Covilhã. Doc on-line, n. 6, ago 2009a.

-----. Portugal olhado pelo cinema como centro imaginário de um império: campo/contracampo. Observatorio Journal, n. 10, 2009b, p. 164-178.

POWER, Marcus. Post-colonial cinema and the reconfiguration of Moçambicanidade. Lusotoipie, 2004. P. 261-278.

ROCHA, Adriano. O cinema chega as montanhas de Minas.

REYNOLDS, Glenn. Colonial cinema in Africa: origins, images, audiences. North Caroline: MacFarland Company, Inc. Publishers, 2015. (em https://books.google. com.br/books?id=bL3eCQAAQBAJ\&pg=PA22\&lpg=PA22\&dq=sal\%C3\%A3o+edis on+-+louren\%C3\%A7 o+marques+-+cinematographo\&source=bl\&ots=ZC6dJVesJ $8 \& \mathrm{~s}$ i g $=\mathrm{Y} \mathrm{u} \mathrm{y} 1$ x N e h T BR\&sa $=$ X\&ved=0CCQQ6AEwAWoVChMI1f7 wwaqexwIVwROQCh0ybwln ${ }^{*} \mathrm{v}=$ on epage \&q=sal\%C3\%A30\%20edison\%20-\%20louren\%C3\%A7o\%20marques\%20-\%20 cinematographo\&f=false)

"Salão Edison", Vida Nova, Lourenço Marques, 01/08/1908.

"Teatro Gil Vicente e os cinematógrafos", em http://maputo120anos.9f.com/gil.htm, acesso em 10/08/2015 (que tem como fonte José Maria Mesquitela, o Arquivo Vivo de Moçambique).

VIEIRA, Silvia. Um cinema de persistência: o cinema moçambicano de ficção (19752011). Dissertação. Universidade do Algarve, 2011.

VIEIRA, Thomaz. O homem que morreu 4 vezes... Memórias de um actor. Viseu: Éden Gráfico, 1967. 